\title{
Assessment of poststroke mania and diagnosis
}

This article was published in the following Dove Press journal:

Neuropsychiatric Disease and Treatment

2I February 2017

Number of times this article has been viewed

\author{
Maria Shoaib' \\ Muhammad Aadil ${ }^{2}$ \\ 'Department of Medicine, DOW \\ Medical College, Karachi, Pakistan; \\ ${ }^{2}$ Department of Psychiatry, Rush \\ University Medical Center, Chicago, \\ IL, USA
}

\section{Dear editor}

We would like to applaud the authors of the case report "Post-stroke emotional incontinence or bipolar disorder?" which highlights a rare yet treatable condition of mania and emotional incontinence after a cerebrovascular accident. We would like to add our views regarding poststroke mania supporting the significant psychiatric distress patients suffer. As the review mentions, psychiatric sequelae of stroke and cerebrovascular disease include anxiety, psychosis, posttraumatic stress disorder (PTSD), and poststroke depression (PSD). ${ }^{1}$ This case report also mentions development of treatment response to selective serotonin reuptake inhibitors, which also shows that poststroke emotional incontinence is related predominantly to serotonergic system dysfunction. $^{2}$

Mania is reported as an unusual manifestation after cerebrovascular accidents; its frequency is $<1 \%$ in comparison with depression and other mood disorders. ${ }^{3}$ Mania is a state of abnormally elevated arousal, affect and energy level. In 1978, Krauthammer and Klerman ${ }^{4}$ introduced the concept of secondary mania. This term refers to the onset of symptoms that meet the diagnostic criteria for mania produced by neurological, metabolic, or toxic disorder. ${ }^{5,6}$ The term secondary mania proposed by Krauthammer and Klerman was also based on the following symptoms: 1) symptoms duration of at least 1 week; 2) presence of elevated or irritable mood; 3) presence of at least two of the following symptoms: hyperactivity, pressured speech, flight of ideas, grandiosity, decreased sleep, distractibility, and lack of judgment; and 4) no history of manic depressive or other affective illness and symptoms of a confused state (such as delirium) co-occurring with the mania. ${ }^{4}$

Lesions responsible for poststroke mania can be located in the thalamus, caudate nucleus, and temporal, parietal, and frontal lobes. Mania seems to be more associated with right-sided lesions; however, there are also reports of mania following left-sided lesions. ${ }^{6,7}$ The temporal relationship between stroke and mania ranged from immediately preceding stroke till 2 years. ${ }^{5}$ In this case, magnetic resonance imaging showed right-sided stroke and the presence of multiple acute lacunar infarcts of lenticulocapsular and right semiovale regions. ${ }^{2}$

As per the Diagnostic and Statistical Manual of Mental Disorders, Fifth Edition $(D S M V)$ criteria, poststroke mania is diagnosed if it includes the following features. 1) A prominent and persistent disturbance in mood predominates in the clinical picture and is characterized by elevated, expansive, or irritable mood. 2) There is evidence from the history, physical examination, or laboratory findings that the disturbance is the direct physiological consequence of a stroke. 3) The disturbance is not accounted for by another mental disorder. 4) The disturbance does not occur exclusively during the course of a delirium. 5) The symptoms cause clinically significant distress
Correspondence: Muhammad Aadi Department of Psychiatry, Rush University Medical Center, II 37 S Taylor, Oak Park, Chicago 60304, IL, USA

Email muhammad.aadil9@gmail.com 
or impairment in social, occupational, or other important areas of functioning. ${ }^{8}$

Consider poststroke mania in any manic patient who presents with neurological focal deficits and is older than expected for the onset of primary mania. It is hence very important to do a proper mental assessment of poststroke patients starting with Mini-Mental State Examination (MMSE) initially, fitting in the $D S M$ criteria for mania, excluding all other causes of bias such as family or previous history, drugs, and so on. A fully blown maniac episode can easily be identified; however, hypomania often tends to be missed; to get over this, a physician must take a detailed interview from the patients by using the Mood Disorder Questionnaire (MDQ) to aid in a definite diagnosis. ${ }^{9}$ Any patient with mood complaints should be evaluated with MDQ; this is a recent, psychometrically validated self-report screening instrument for bipolar spectrum disorders. It is based upon yes/no items covering all DSM IV symptoms of manic/hypomania; it has developed as an important screening tool over the times with a high sensitivity and commendable specificity.

Immediate assessment of any prevailing mood disorder, particularly mania in poststroke patients, is needed to prevent the disease progression and also limit its later onset reducing morbidity of life. ${ }^{4}$

\section{Disclosure}

The authors report no conflicts of interest in this communication.

\section{References}

1. Capaldi VF 2nd, Wynn GH. Emerging strategies in the treatment of poststroke depression and psychiatric distress in patients. Psychol Res Behav Manag. 2010;3:109-118.

2. Mnif L, Sellami R, Masmoudi J. Post-stroke emotional incontinence or bipolar disorder? Neuropsychiatr Dis Treat. 2016;12:1883-1885.

3. Huffman JC, Stern TA. Poststroke neuropsychiatric symptoms and pseudoseizures: a discussion. Prim Care Companion J Clin Psychiatry. 2003;5(2):85-88

4. Krauthammer C, Klerman GL. Secondary mania: manic syndromes associated with antecedent physical illness or drugs. Arch Gen Psychiatry. 1978;35(11):1333-1339.

5. Celik Y, Erdogan E, Tuglu C, Utku U. Post-stroke mania in late life due to right temporoparietal infarction. Psychiatry Clin Neurosci. 2004; 58(4):446-447.

6. Starkstein SE, Boston JD, Robinson RG. Mechanisms of mania after brain injury. 12 case reports and review of the literature. J Nerv Ment Dis. 1988; 176(2):87-100.

7. Kang SY, Paik JW, Sohn YH. Restlessness with manic episodes due to right parietal infarction. J Mov Disord. 2010;3(1):22-24.

8. American Psychiatric Association [webpage on the Internet]. Diagnostic and Statistical Manual of Mental Disorders (DSM-5®). 2013. Available from: http://dsm.psychiatryonline.org/doi/book/10.1176/appi. books.9780890425596. Accessed February 7, 2017.

9. Hirschfeld R, Vornik LA. Recognition and diagnosis of bipolar disorder. J Clin Psychiatry. 2004;65(15):5-9.

Dove Medical Press encourages responsible, free and frank academic debate. The content of the Neuropsychiatric Disease and Treatment 'letters to the editor' section does not necessarily represent the views of Dove Medical Press, its officers, agents, employees, related entities or the Neuropsychiatric Disease and Treatment editors. While all reasonable steps have been taken to confirm the content of each letter, Dove Medical Press accepts no liability in respect of the content of any letter, nor is it responsible for the content and accuracy of any letter to the editor.

\section{Publish your work in this journal}

Neuropsychiatric Disease and Treatment is an international, peerreviewed journal of clinical therapeutics and pharmacology focusing on concise rapid reporting of clinical or pre-clinical studies on a range of neuropsychiatric and neurological disorders. This journal is indexed on PubMed Central, the 'PsycINFO' database and CAS, and is the official journal of The International Neuropsychiatric Association (INA). The manuscript management system is completely online and includes a very quick and fair peer-review system, which is all easy to use. Visit http://www.dovepress.com/testimonials.php to read real quotes from published authors. 